SCIDic

\section{Effect on Communication Ability of Dental Hygienist in Problem-Solving Ability: Focusing on the} Modulatory Effect of Cooperative Self-Efficacy

Research Article

Kyeung-Ae Jang ${ }^{1}$, Se Hyun Hwang ${ }^{2}$, Soon-Jeong Jeong ${ }^{3 *}$

${ }^{1}$ Department of Dental Hygiene, College of Health and Welfare, Silla University, Busan, 46958 Korea,

${ }^{2}$ Department of Dental Hygiene, Dongju College, Busan 49318, Korea.

${ }^{3}$ Department of Dental Hygiene \& Institute of Basic Science for Well-Aging, Youngsan University, Yangsan 50510, Korea.

\title{
Abstract
}

Purpose: This study investigated the effect on the communication ability of dental hygienists on problem-solving ability, focusing on the modulatory effect of cooperative self-efficacy.

Materials and Methods: The study was conducted from November 4 to December 20, 2019, and it involved 213 dental hygienists working in the Busan, Ulsan, and Gyeongnam regions in Korea. The collected data were analyzed using SPSS 25.0 program. The general characteristics were analyzed using frequency analysis, the average score of each variable was analyzed using means and standard deviation, and the relevance of each variable was analyzed using correlation analysis. Hierarchical regression analysis was used to investigate the modulatory effect of cooperative self-efficacy.

Results: Communication ability $(\mathrm{p}<.01)$, cooperative self-efficacy $(\mathrm{p}<.01)$, and problem-solving ability $(\mathrm{p}<.01)$ of dental hygienists showed significant correlations.As a result of cooperative self-efficacy analysis, in case of positive self-efficacy, the effect of communication ability on problem-solving ability was significant $(\mathrm{p}<.01)$. Cooperative self-efficacy was significant, as it partially mediated the relationship between communication ability and problem-solving ability $(\mathrm{p}<.001)$.

Conclusion: This study provides basic data for improvingproblem-solving ability and effective communication with patients and subjects by improving the cooperative self-efficacy of dental hygienists.

Keywords: Communication Ability; Cooperative Self-Efficacy; Dental Hygienist; Problem-Solving Ability.

\section{Introduction}

The Korean society has a demand for talented individuals who can respond flexibly and act quickly in solving problems with others using the expertise and information of members of the organization [1]. In a rapidly changing medical environment, the level of education of patients is increasing, and information acquisition through various media has become easier, and the levels of knowledge and awareness of medical care is high [2,3]. Dental hygienists in charge of clinical practice management and education are required to be cooperative and capable of solving various problems through effective communication within the organization. Communication ability refers to the ability to share messages about one's thoughts and feelings in relationships with others and to effectively accept the messages of others $[4,5]$. In the recent dental environment, dental hygienists should improve their communication ability to actively interact with patients during consultation and treatment [6]. Dental hygienists should resolve potential problems through verbal and nonverbal communication when various situations arise in dental clinical practice [7]. Therefore, communication ability is closely related to problem-solving ability [9]. Problem-solving ability refers to the ability to solve problems quickly, intellectually, and creatively through the recognition of the difference between the current state and the goal to be reached. Dental hygienists should have problem-solving abilities related to patient management and treatment to quickly solve problems related to patient safety [8]. Cooperative self-efficacy is a belief, confidence, or expectation in person's ability to successfully achieve goals. Persons with high self-efficacy have excellent self-control when performing certain actions, and they have good

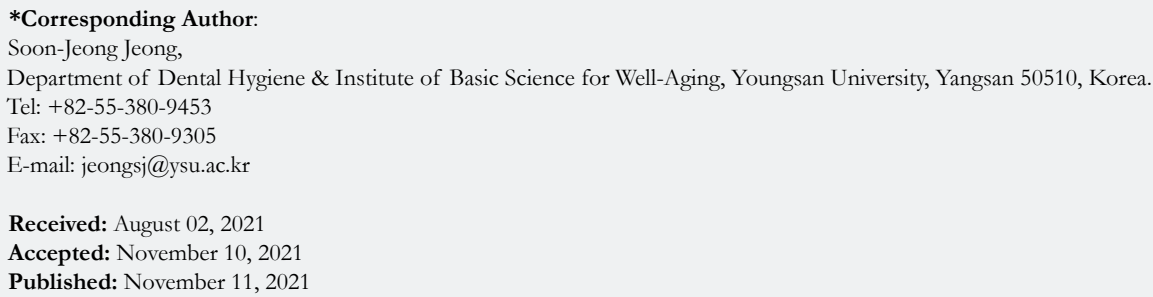

Copyright: Soon-Jeong Jeong ${ }^{\circ}$ 2021. This is an open-access article distributed under the terms of the Creative Commons Attribution License, which permits unrestricted use, distribution and reproduction in any medium, provided the original author and source are credited. 
judgment, which facilitates good decisions makings [9]. A dental hygienist with high self-efficacy will demonstrate confidence and better attitudes and behaviors during the management of patients, which will facilitate good quality of care [10]. Cho and Kim et al. reported that self-efficacy and problem-solving ability have a positive effect on the performance of given tasks [9, 11]. Therefore, enhancing the cooperative self-efficacy of dental hygienists is important, given the demands of dental care and services in the rapidly changing medical environment. Although some studies have analyzed communication ability and problemsolving ability of nurses and dental hygienists [9, 11], only a few of them focused on the effect of communication ability of dental hygienists on problem-solving ability, focusing on the effect of cooperative self-efficacy. Therefore, this study investigates the relationships between communication ability, problem-solving ability, and cooperative self-efficacy for dental hygienists, and the effect of communication ability on problem-solving ability, focusing on the modulatory effect of cooperative self-efficacy. In addition, this study will provide basic data for appropriate methods and strategies for accurately assessing the level of self-efficacy and increasing cooperative self-efficacy, communication ability, and problem-solving ability. This will improve the quality of care and the satisfaction of patients and subjects in dental practices.

\section{Materials and Methods}

\section{Research Design and Subjects}

The subjects of this study were dental hygienists working in dental hospitals and clinics in the Busan, Ulsan and Gyeongnam regions in Korea, and a convenient sampling method was used. Questionnaires were given to dental hygienists who agreed to participate in the study and signed the consent form. The questionnaires were delivered in person at the dental hospitals and clinics, and they were filled between November 4 and December 2, 2019. Based on Cohen's power analysis, the required minimum sample size under the conditions of a significance level of $5 \%$ (two sides), power of $80 \%$, and an effect size of 0.5 , was calculated using $\mathrm{G}^{*}$ power 3.1.3. The minimum sample size required was 200 , and 240 questionnaires were distributed to compensate for dropout. Two hundred and twenty-five dental hygienists responded to the questionnaires. Finally, 213 questionnaires were analyzed, excluding 12 copies with biased or missing responses.

\section{Research Method}

A structured questionnaire was used to collect data for this study. We used a tool developed by Lee at al. [12], to evaluate the questionnaire responses and assess communication ability was composed of 49 questions. The responses to the questions were scored using a Likert 5-point scale, and a high score indicated high communication ability. The modified and supplemented questionnaire of Alavi [13], which consisted of 19 questions, was used to evaluate cooperative self-efficacy. Each question was framed to allow the response to be scored on a Likert 5-point scale, with higher scores indicating higher cooperative self-efficacy. Negative content in each category was analyzed by reverse coding for the consistency of the questionnaire.

\section{Data Analysis}

The SPSS statistical program (ver. 25.0, IMB, Armonk, NY, USA) was used to analyze the data of this study. The general characteristics of the study subjects were presented using frequency and percentage, whereas the scores of communication ability, problem-solving ability, and cooperative self-efficacy were presented as mean \pm standard deviation. The relationshipsbetween the factorswere analyzed for significance using correlation analysis, and the modulatory effect of cooperative self-efficacy was analyzed for significance using hierarchical regression analysis, including the interaction of the independent and the control variables. Mediation effect analysis and Sobel test were additionally conducted. Cronbach's $\alpha$ of the test tool of this study was 0.829 for communication ability, 0.936 for problem-solving ability, and 0.940 for cooperative self-efficacy. The reliability coefficient was 0.80 or higher, indicating a high degree of internal consistency of the questionnaire tool.

\section{Results}

The general characteristics of the study subjects are shown in Table 1 . Most of the participants were women (95.3\%). The age distribution was as follows: $25-29$ years old were $53.1 \%$; 30-39 years old, 38.5\%, 40 years old, $8.4 \%$. Regarding the academic background of the participants: $62.9 \%$ graduated from technical college, $31.0 \%$ graduated from university, $6.1 \%$ were graduates and postgraduates. Regarding the total clinical experience, $32.9 \%$ had less than 3 years, 36.6\% had less than 3-7 years and 30.5\% had 7 years or more of experience.

The scores for communication ability, cooperative self-efficacy, and problem-solving ability are shown in Table 2 . The scores were 3.12 points for communication ability, 3.28 point for cooperative self-efficacy, and 3.40 points for problem-solving ability.

Correlation analysis results of dental hygienist communication ability, cooperative self-efficacy, and problem-solving ability are shown in Table 3. Communication ability showed a statistically significant positive $(+)$ correlation with cooperative self-efficacy $(\mathrm{r}=0.342)$ and problem-solving ability $(\mathrm{r}=0.527)$. Cooperative self-efficacy showed a statistically significant positive $(+)$ correlation with problem-solving ability $(r=0.624)$.

The moderating effect of cooperative self-efficacy on the effect of communication ability on problem-solving ability is shown in Table 4. Amoderated regression analysis was used to evaluate the moderating effect of cooperative self-efficacy on communication ability and problem-solving ability, and cooperative self-efficacy was found to be significant. On analyzing the main effects of communication ability, the magnitude of the effect of communication ability on problem-solving ability was 0.255 . The analysis of the moderating effect of cooperative self-efficacy revealed that the magnitude of the interaction between communication ability and cooperative self-efficacy was .912. This means that the influence of communication ability on problem-solving ability increases with increasing cooperative self-efficacy.

The results of the hierarchical regression analysis of the mediating effect of cooperative self-efficacy on the effect of communication ability on problem-solving ability are shown in Table 5. During the first stage, communication ability significantly affected problem-solving ability $(\beta=0.527, \mathrm{p}<0.001)$. During the second 
Table 1. General characteristics of subjects.

\begin{tabular}{|c|c|c|c|}
\hline Classification & Categories & $\mathbf{N}$ & $\mathbf{\%}$ \\
\hline \multirow{3}{*}{ Sex } & Female & 203 & 95.3 \\
\cline { 2 - 4 } & Male & 12 & 4.7 \\
\hline \multirow{4}{*}{ Age } & $25 \sim 29$ & 113 & 53.1 \\
\cline { 2 - 4 } & $30 \sim 39$ & 82 & 38.5 \\
\cline { 2 - 4 } & Over 40 & 18 & 8.4 \\
\hline \multirow{4}{*}{ Final education } & College graduate & 134 & 62.9 \\
\cline { 2 - 4 } & University graduation & 66 & 31 \\
\cline { 2 - 4 } & Graduate or above & 13 & 6.1 \\
\hline & Less than 3 years & 70 & 32.9 \\
\cline { 2 - 4 } & Less than 3-7 years & 78 & 36.6 \\
\cline { 2 - 4 } & Over 7 years & 65 & 30.5 \\
\hline & Total & 215 & 100 \\
\hline
\end{tabular}

Table 2. Degree of communication ability, cooperative self-efficacy, and problems solving ability.

\begin{tabular}{|c|c|}
\hline Classification & $\begin{array}{c}\mathbf{M} \pm \text { SD } \\
(\mathbf{n}=\mathbf{2 1 3})\end{array}$ \\
\hline Communication ability & $3.12 \pm 0.29$ \\
\hline Cooperative self-efficacy & $3.28 \pm 0.53$ \\
\hline Problem-solving ability & $3.40 \pm 0.40$ \\
\hline
\end{tabular}

Table 3. Correlation between communication ability, cooperative self-efficacy, and problems solving ability.

\begin{tabular}{|c|c|c|c|}
\hline & $\begin{array}{c}\text { Communication } \\
\text { ability }\end{array}$ & $\begin{array}{c}\text { Cooperative } \\
\text { self-efficacy }\end{array}$ & $\begin{array}{c}\text { Problem-solving } \\
\text { ability }\end{array}$ \\
\hline Communication ability & - & & \\
\hline Cooperative self-efficacy & $.342^{* *}$ & - & \\
\hline Problem-solving ability & $.527^{* *}$ & $.624^{* *}$ & - \\
\hline \multicolumn{4}{|r}{$\mathrm{*}<0.01$}
\end{tabular}

The data were analyzed by person correlation coefficient.

Table 4. Modulatory effect of cooperative self-efficacy on the effect of communication ability in problem-solving ability.

\begin{tabular}{|c|c|c|c|c|c|c|c|}
\hline \multirow{2}{*}{ Variable } & \multicolumn{3}{|c|}{ Model I } & & \multicolumn{3}{|c|}{ Model II } \\
\hline & B & $\beta$ & $\mathbf{t}$ & & B & $\beta$ & $\mathbf{t}$ \\
\hline Communication ability $(\mathrm{X})$ & 0.498 & 0.073 & $6.852^{* * *}$ & & 1.277 & 0.912 & $3.675^{* * *}$ \\
\hline Cooperative self-efficacy (M) & 0.38 & 0.039 & $9.693 * * *$ & & 1.155 & 1.528 & $3.394 * *$ \\
\hline $\begin{array}{c}\text { Communication ability }{ }^{*} \\
\text { Cooperative self-efficacy (XM) }\end{array}$ & & & & & 0.243 & 1.328 & $2.292^{*}$ \\
\hline $\mathrm{R}^{2}\left(\Delta \mathrm{R}^{2}\right)$ & \multicolumn{3}{|c|}{0.501} & 3 & \multicolumn{3}{|c|}{$0.513(0.012)$} \\
\hline $\mathrm{F}$ & \multicolumn{3}{|c|}{$81.182^{* * *}$} & & \multicolumn{3}{|c|}{$93.953 * * *$} \\
\hline
\end{tabular}

The data were analyzed by hierarchical regression analysis.

Dependent variables: Problem solving ability, ${ }^{* *} \mathrm{p}<0.001,{ }^{*} \mathrm{p}<0.01,{ }^{*} \mathrm{p}<0.05$

stage, communication ability was significantly associated with the mediating variable, cooperative self-efficacy $(\beta=0.120, \mathrm{p}<$ 0.001.). During the third stage, where the independent and mediating variables were analyzed together, cooperative self-efficacy was significant as a mediating variable $(\beta=0.503, \mathrm{p}<0.001$.$) , and$ the $\beta$ coefficient of the independent variable was also significant $(\beta=0.355, \mathrm{p}<0.001)$. This means that cooperative self-efficacy partially mediates the relationship between communication ability and problem-solving ability. The analysis of the mediating effect showed that the mediating effect of cooperative self-efficacy was significant.

\section{Discussion}

This study investigated the degrees of communication ability, cooperative self-efficacy, and problem-solving ability of dental 
Table 5. Mediating effect of cooperative self-efficacy on the effect of communication ability in problems solving ability.

\begin{tabular}{|c|c|c|c|c|c|c|}
\hline Step & Model & B & SE & $\beta$ & $\mathbf{t}$ & $\mathbf{R}^{2}$ \\
\hline 1 & Communication ability / Problem- solving ability & 0.738 & 0.082 & 0.527 & $9.010^{* * *}$ & 0.278 \\
\hline 2 & Communication ability / Cooperative self-efficacy & 0.633 & 0.12 & 0.342 & $5.280^{* * *}$ & 0.117 \\
\hline \multirow{2}{*}{3} & Communication ability / Problem-solving ability & 0.498 & 0.073 & 0.355 & $6.851 * * *$ & \multirow{2}{*}{0.501} \\
\cline { 2 - 6 } & Cooperative self-efficacy / Problem-solving ability & 0.38 & 0.039 & 0.503 & $7.693^{* * *}$ & \\
\hline
\end{tabular}

$* * * \mathrm{p}<0.001$

hygienists, and the effect of communication ability on problemsolving ability focusing on the modulatory effect of cooperative self-efficacy. The mean scores of the dental hygienists were 3.40 points for problem-solving ability, 3.28 points for cooperative self-efficacy, and 3.12 points for communication ability(Table 2). The communication ability score of dental hygienists in the study by Lee et al. [12] was 3.63 points, 3.44 points in the study of nurses from Jeong and Shin [14], and 3.34 points in the study by Lim and Kim [15]. The communication ability score of Korean dental hygienists in this study, was lower than that of the previous report. Communication ability is essential for the interactive role of dental hygienists in solving and practicing real problems. The average score of the creative problem-solving ability of the dental hygienists was 3.40 points, whereas the score of cooperative self-efficacy was 3.27 points in the study by Kim and Sim [6], which was similar to the results of this study. Problem-solving ability affects the speed and efficiency of decision making when solving a given problem, whereas cooperative self-efficacy affects job satisfaction and organizational commitment [6]. Therefore, communication ability, cooperative self-efficacy, and problemsolving ability are necessary for dental hygienists, and continuous improvement and enhancement of these capabilities through education and seminars are required. Based on the analysis, cooperative self-efficacy had the highest statistically significant positive correlation with problem-solving ability $(\mathrm{p}<0.01)$ (Table 4$)$, and communication ability showed the highest statistically significant positive $(+)$ correlation with problem-solving ability $(\mathrm{p}<0.01)$, followed by cooperative self-efficacy $(\mathrm{p}<0.01)$ (Table 4).Park and Ko [16] reported that communication ability was significantly valuable during problem-solving, and their results were similar to the results of this study. In addition, the study of Yun et al. [17] reported that the communication ability of nurses has a great influence on patient safety competencies.

This is thought to be because communication ability enhances problem-solving ability in the medical environment. To improves the job performance of dental hygienists, it is necessary to improve the problem-solving ability in the evidence-based practice of dental hygiene [4]. It is believed that various problems can be solved in the field of dental clinical practice, and effective communication is key to increasing cooperative self-efficacy. Communication ability affects the moderating effect of cooperative self-efficacy and problem-solving ability, focusing on the mediating effect.In other words, high cooperative self-efficacy has a great positive effect on problem-solving ability, whereas communication ability has a positive effect on problems solving ability. Based on the high cooperative self-efficacy of dental hygienists, it is necessary to share information through participatory education and seminars to positively improve communication and problemsolving abilityby enhancing cooperative self-efficacy using various programs in the workplace. Furthermore, effective communication will facilitate a better quality of dental care to patients and subjects and induce positive effects on medical satisfaction. This study was involved dental hygienists working in dental hospitals and clinics in the Busan, Ulsan and Gyeongnam regions, and it is difficult to expand and interpret or generalize the results of dental hygienists in Korea and other countries. This study provides important basic data for appropriate measures and strategies for increasing cooperative self-efficacy, communication ability, and problem-solving ability.

\section{Conclusion}

This study confirmed the effect of communication ability on problem-solving ability, focusing on cooperative self-efficacy, based on the results of the analysis of the relationships between communication ability, cooperative self-efficacy, and problemsolving ability of dental hygienists. The communication ability of dental hygienists has a positive effect on problem-solving ability and cooperative self-efficacy. Therefore, communication ability can be an appropriate target for improving problem-solving ability. Furthermore, effective communication of dental hygienists will induce a positive effecton problem-solving during the consultation and treatment of patients and subjects.

\section{References}

[1]. Blumberg P. Evaluating the evidence that problem-based learners are self directed learners: are view of the literature. In Evenson DH \& Hmelo CE (eds.). Problem based learning: a research perspective on learning interactions. Lawrence Erlbaum Associates. 2000;199-226.

[2]. Greaves D, Evans M. Medical humanities. Medical Humanities. 2000 Jun $1 ; 26(1): 1-2$

[3]. So YR, Baik BJ, Kim JG, Yang YM, Lee YH. The attitude survey of orthodontic patients' parents at chonbuk national university hospital, the department of pediatric dentistry. J Korean Acad Pediatr Dent 200835:487-493.

[4]. Jo HI, Lee MH. The mediating effect of prosocial behavior in the relation between empathic ability and psychological wellbeing. Korean Youth Res Assoc 201017:139-158.

[5]. Papa MJ. Communicator competence and employee performance with new technology: A case study. Southern Communication Journal 198955:87101.

[6]. Kim DY, Jang KA. Effects of the 4C core competencies on work ability among dental hygienists. J Dent Hyg Sci 201919:220-227.

[7]. Lee JE, Lee SY, Kim HJ. The effects of critical thinking disposition and problemsolving ability on the work performance assessment of dental hygienists. J Dent Hyg Sci 201717:275-282.

[8]. Kim HS, Han SJ. The survey on the influence of clinical nurse's critical thinking disposition, problem-solving skill and self-efficacy on patients safety competencies. J Korea Acad Inst 201617: 598-608.

[9]. Jho MY. Effects of the type of writing reflective journals on academic self-efficacy and problem solving ability in nursing students taking a fundamental nursing skills course. Journal of Korean Data Analysis Society 201719:28252839.

[10]. Jang KA. Effects of dental hygiene students and self-efficacy on problem solving ability. Journal of Korean Society of Oral Health Science 20197:59- 


\section{3.}

[11]. Kim YH, Kim YG. The influence of academic self-efficacy, and critical thinking disposition on problem solving ability of nursing students. Journal of the Korea Academia-Industrial cooperation Society 201617:589-598.

[12]. Lee SM, Yun JW, Lee JH. Communication competence in dental healthcare hygienists. J Korean Soc Dent Hyg 202020:359-67.

[13]. Alavi SB, McCormick J. The roles of perceived task interdependence and group members' interdependence in the development of collective efficacy in university student group contexts. Br J Educ Psychol. 2008 Sep;78(Pt 3):375-93. PubMed PMID: 17845739

[14]. Jung GH, Shin SH. Affecting factors of nurses' communication. J East West
Nurs Res 201117: 164-170.

[15]. Im SB, Kim EK. Interpersonal communication and difficult communication experiences of preceptor nurse. J Korean Acad Psych Mental Health Nurs 200817:471-480.

[16]. Park JH, Go JW. Relationship between collaborative self-efficacy and problem-solving skills of university students: mediating effect of communication skills. J of Educational Innovation Research 201626:169-192.

[17]. Yoon SH, Lee T W, Maeng SJ, Kwon JE. The influence of nurses' communication competency, critical thinking disposition, and perception of patient safety culture on patient safety competency in armed forces hospitals. Korean J Occup Health Nurs 202029:123-132. 